\title{
FUTURE APPLICATION OF METEOROLOGY IN FIRE CONTROL ${ }^{1}$
}

\author{
By D. E. WILLIAMS
}

\section{INTRODUCTION}

When I was asked to give a paper on this subject, I was somewhat surprised, as I went from one aspect of fire control to another, at the varied influence weather has in almost all phases of fire control and, for that matter, in almost all phases of forestry. Earlier in this meeting you have heard water referred to as the common thread in the fabric of resource management. In the same vein, one could describe weather as the mantle which touches and influences all phases of forestry.

Because weather influences so much in fire control, I will have to confine my remarks to only some of the areas where advances are being made. I hope that subsequent discussions will illustrate others.

\section{DANGER Rating}

Although wind and rain had long been recognized as having a great influence on the behaviour of forest fires, it was not until the 1920's that serious thought was given in this country to the systematic use of weather data to achieve an estimate of the level of fire danger. Since that time, fire-danger tables for all parts of Canada have evolved from studies of the relationships between weather, fuel moisture and fire behaviour. Currently, the Canadian system is being reviewed and will be revised to include a number of improvements. Among the most important of these are:

(a) a 0 to 100 point scale based on fire severity

(b) an improved drought index

(c) inclusion of more weather factors for improved accuracy

Danger Forecasting

The forecasting of future fire danger follows naturally from the danger rating itself. A system of forecasting was developed by Mr. Paul in the Maritimes and described at the $1963 \mathrm{CIF}$ Annual Meeting in Halifax. The system has been further refined and is being put into operation in Quebec under Mr. Pouliot, who will issue regular forecasts beginning next spring. This program is still experimental and we expect that a number of important improvements will be made. After that, if other provinces wish, the system could be expanded into a Canada-wide fire danger forecasting network with forecast indexes for all forest areas of Canada being computed by machines in one or two centres.

\section{Automatic Reporting Stations}

One of the keys to the success of a fire danger rating and forecasting system is a weather station network that gives full coverage to all important forest

\footnotetext{
${ }^{3}$ Paper delivered at the 58 th Annual Meeting, Canadian Institute of Forestry, Banff, Alberta. ${ }^{2}$ Director, Fire Research Institute, Department of Forestry and Rural Development, Ottawa, Ontario.
} 
areas. Only in a few parts of the country do we have such a network and, with aircraft replacing lookouts in some regions, stations, formerly operated by lookout men, will have to be replaced in some way. Perhaps the answer to both situations is the use of remote weather stations that will automatically transmit the necessary data at predetermined times or on call. Such stations are available now and could be easily tied in with the computerized forecasting system mentioned in the previous paragraph, but they are expensive at the present time.

Another possibility here is a fire danger machine that will take its own weather readings and calculate the danger index automatically. An early prototype of such a machine has been developed by the National Research Council and will be field-tested soon.

\section{Special Fire Weather Warnings}

The development of fire weather forecasting has been assisted greatly by the spirit of co-operation that has existed between the D.O.T. forecasters and the fire control men. Each has learned from the other. Forecasters trained largely in aviation and public weather forecasting had to learn the special needs of the fire control men. They, in turn, had to learn to understand the forecasts and how to apply the information they contain. There is room for even greater co-operation in the pinpointing of periods of particularly severe fire weather so that special "action stations" forecasts can be issued. Such periods do not occur often, but when they do they often are responsible for a large proportion of the fire loss for a particular season. If special forecasts are to be effective, co-operative studies should be begun between forecasters and fire researchers to find the combination of forecastable factors that must be used to prepare the special warnings. Each factor of fire weather should be studied in depth to determine how much and in what way each contributes to fire danger and what important interactions exist among them.

\section{Prescribed Burning}

Much of what has been said in the previous paragraph applies in prescribed burning. A prescription for burning is, in a sense, a forecast in reverse. That is, certain fire danger and fire weather conditions are specified for the burn and the operator must then wait until these conditions are met by the weather systems. As for the special weather forecasts, the more that is known about each factor's influence on a fire, the more useful the prescription can be.

\section{Weather Modification}

Although the results of cloud-seeding experiments to increase precipitation have not been encouraging, there is no doubt that artificial nucleation of clouds can produce cloud dissipation and precipitation under some conditions. Reduction of lightning has shown promising results in Project Skyfire, conducted by the U.S. Forest Service. It has been reported that Skyfire experiments have produced a reduction of more than 30 per cent in cloud to ground lightning. Further efforts in these fields may produce a national or even international system of weather modifications that will round the sharp points of weather extremes. 


\section{Long Range Forecasts}

Two recent developments - the ultra-high-speed electronic computer and the weather satellite - have placed the problem of long-term forecasts in an entirely new light. Tremendous quantities of weather data can be analysed by computers at a rate previously impossible and the weather satellites, becoming more sophisticated with each generation - Tyros is old hat now - are able to present the forecasters with a picture of continent-wide weather patterns.

The first weather satellite went into orbit in 1960 , and sent back pictures of the top side of the weather scene that were of a quality beyond the expectations of its designers. Since that time many more weather satellites have been placed in space and, of these, six are still in operation. The latest satellite, ESSA II, is in a near-polar orbit and is able to photograph the cloud cover of the entire world every 24 hours. It takes pictures whenever it is over daylit terrain and automatically transmits them to receiving stations in the United States and Canada. Both these important tools, the electronic computer and the weather satellite, are steadily being improved and the day may soon be here when the two will link together to give the forecaster the information he needs to prepare the accurate long-range forecasts that many of us have been hoping for.

\section{Weather Radar and SFerics}

Radar has long been used to locate and track thunderstorms for the information of fire control officers. Operators of military radar of the early-warning system have co-operated in several provinces in supplying storm data whenever their other duties would permit. More recently, however, special weather radar has been designed and the Canadian Meteorological Branch has established a network of weather radar that covers the more inhabited parts of the country, with military radar still providing information when possible to help fill in some of the gaps in the existing network. Other special radar equipment is being used in various weather research projects. In the D.O.T. network, radar readings are taken hourly and the information is sent in to the central analysis office. Future plans call for the hourly transmission of a facsimile of the radar screen from each set in the network. The composite of these will give a picture of cloud and storm conditions across the country. When these can be synchronized with satellite picture coverage, a very comprehensive overview of the weather will be realized.

Although radar can locate and track storm centres and delineate precipitation, it cannot distinguish active lightning storms from inactive ones. This is where a branch of radio known as "sferics" enters the picture. Sferics equipment can detect lightning strokes and indicate their direction. Some of the more recent models are said to be able to distinguish between cloud-to-ground and cloud-to-cloud strokes. Thus, when sferics is used in conjunction with radar, the operator is able to determine which storm cells are producing rain and/or lightning and which are inactive and, from this, plot the track of the potentially dangerous lightning storms. These tracks are, of course, useful to fire control agencies, which can adjust their detection activity to concentrate on the storm paths. 
Sferics, unlike radar is not "line of sight"; it has a range of several thousand miles; thus, more than one set is needed to obtain a fix in a storm. It is, however, much less expensive than radar.

In Alberta, a meteorologist has developed an air-stability index with which to predict lightning probability. The results to date have been encouraging.

\section{Meteorology of a Fire}

Fires themselves have an effect on their environment and many of these effects are not too well understood. Several studies are under way in Canada and these range from observations of the air currents around a small laboratory fire at Waterloo University to the effects of prescribed burns, including crown fires, at the Petawawa Forest Experiment Station.

On an even larger scale, project "Flambeau", a study of mass fire, is a co-operative project involving forestry and civil defence people from the United States, Britain, Australia and Canada. Many of the data being collected at these large fires are meteorological in nature and will certainly lead to a better understanding of the "blow-up" type of fire.

\section{CoNClusron}

In the time available to me I have been able to mention only some of the interesting developments in forest-fire meteorology that are with us or are on the horizon. There are many others. Meteorology is moving fast under the propulsion of modern technology and in recent years, as I have noted earlier, there has been an ever increasing bond of co-operation between meteorologists and foresters, particularly in forest protection, although I must say that meteorology is now receiving much greater attention in other fields of forestry too. We foresters, however, must recognize that co-operation works both ways. I do not feel that we have done enough in supplying the meteorologist with good forest weather data. Fire danger forecasts, for example, will not be as good as they can be if foresters do not ensure that their weather stations are equipped with well-maintained instruments and that the weather readings are taken, recorded and transmitted accurately and conscientiously. A tremendous number of dollars and man hours of highly skilled effort have resulted in the sophisticated weather tools I have mentioned. Surely it makes economic sense for forestry to spend a little more money and effort on weather-data collection, where it will guarantee us a greater harvest of benefits from these tools. 